\title{
Musculoskeletal Attendances to a Minor Injury Department During a Pandemic
}

\author{
Richard J. Dowell ${ }^{1}$, Neil Ashwood ${ }^{2}$, Jamie Hind ${ }^{3}$ \\ 1. Emergency Department, University Hospitals of Derby and Burton, Derby, GBR 2. Trauma and Orthopaedics, \\ University Hospitals of Derby and Burton, Derby, GBR 3. Trauma and Orthopaedics, Walsall Manor Hospital, Walsall, \\ GBR
}

Corresponding author: Richard J. Dowell, richard.dowell1@nhs.net

\begin{abstract}
Introduction: As coronavirus disease 2019 (COVID-19) became a public health emergency of international concern, countries across the globe began to instate strict social distancing restrictions or "lockdowns". During these times emergency departments in the United Kingdom (UK) recorded a significant drop in patients attending when compared to the same months of previous years. Attendances related to musculoskeletal (MSK) trauma also saw a significant drop in numbers
\end{abstract}

Objective: The purpose of this retrospective audit was to investigate patterns of injuries attending during the pandemic and more specifically during times of lockdown.

Method: Retrospective audit data was collected from an electronic medical record system (MediTech V6) during the time period of the first lockdown in the UK. Data was collected for patients attending the emergency department at the Queens Hospital Burton site of the University Hospitals of Derby and Burton National Health Service (NHS) Trust. Presenting complaints were recorded for the entire emergency department, and diagnosis on discharge and activity status was recorded for minor injuries only. This data was then compared to the same date from 2019.

Results: Overall attendances in the emergency department decreased by $45.42 \%$ during the first lockdown when compared to the same time period in 2019. MSK problems also saw a significant drop as back pain decreased by $58.88 \%$, neck pain fell by $78.52 \%$ and limb problems decreased by $59.74 \%$. When comparing data from the minor injury department, limb problems decreased by $20.45 \%$. The number of soft tissue injuries decreased by $24.05 \%$ and fractures decreased by $7.96 \%$.

Conclusion: Attendances in the emergency department were greatly reduced during the COVID-19 pandemic, especially during the first lockdown. The rates of fractures and soft tissue injuries within the minors' area of the emergency department were also reduced but not at the same rate as the overall attendance. A large number of fractures and soft tissue injuries still presented to the emergency department despite reduced national activity. These attendances may be as a result of the increased rate of Do It Yourself (DIY)-related injuries and altered patient/social behaviour due to lockdown, social distancing, and seasons/weather. Further research would be required to investigate the changing patterns of behaviour especially as we enter a second wave of cases.

Review began 01/26/2021 Review ended 02/04/2021 Published 02/05/2021

\section{() Copyright 2021}

Dowell et al. This is an open access article distributed under the terms of the Creative Commons Attribution License CC-BY 4.0., which permits unrestricted use, distribution, and reproduction in any medium, provided the original author and source are credited.
Categories: Emergency Medicine, Orthopedics, Public Health

Keywords: musculoskeletal injuries, msk injuries, minor injuries, fractures, emergency department attendances, covid 19

\section{Introduction}

In December 2019, in Wuhan, Hubei province, China, the first case of coronavirus disease 2019 (COVID-19) was reported [1]. By January 31, COVID-19 had spread to 19 countries [2] and was declared a public health emergency of international concern by the World Health Organisation (WHO) [3]. The first cases of COVID19 diagnosed in the United Kingdom (UK) were made the week commencing January 27, 2020 [4]. At this time the virus had spread significantly with over 7,000 cases in China and 90 cases elsewhere [5]. Evidence suggested that the mode of transmission of COVID-19 was human to human [6], with the major route of transmission via respiratory droplets and close human contact [7]. It was declared a global pandemic by the WHO on March 11, 2020 [8]. On March 12 the UK government announced it was moving from the containment phase to the delay phase, preparing the public for the introduction of strict measures of social distancing [9]. By March 23, 2020, COVID-19 claimed 335 lives in the UK and it was at this time when the UK went into "lockdown" whereby strict guidelines were introduced to minimise the spread of the virus [10]. These guidelines promoted social distancing by encouraging the general public to stay indoors, only leaving for essential shopping, medical needs, and exercise once a day. This meant many people were encouraged to work from home or placed on the Furlough program where workers were paid $80 \%$ of salary whilst staying at home and not working. It was reported 6.3 million UK workers were placed on the Furlough program in early 
May 2020 [11]. On March 20 schools were closed in the UK to the majority of pupils, allowing only the children of healthcare workers to attend [12]. Children of school age were expected to follow the strict guidelines to reduce the transmission rate of the virus.

During the time of strict social distancing guidelines, attendances in the National Health Service (NHS) Emergency Departments decreased by $43.5 \%$ when compared to attendances for the same months in 2019. In 2020 attendances from March 1 to May 31 totalled 6,451,722 across all Emergency Departments and minor injury units across England, attendances decreased to 3,710,218 between the same dates in 2020 [13]. The greatest fall of attendances was during the month of April 2020 whereby the number of people using Emergency Departments decreased to below one million (916,581).

The purpose of this study was to use retrospective data taken from the emergency department to assess which musculoskeletal (MSK) conditions attended the emergency department during a pandemic when compared to the same months of the previous year.

\section{Materials And Methods}

Data was collected from Meditech Version 6, an online clinical operating system allowing electronic documentation, tracking and management of patients attending the emergency department at a single site. Diagnostic codes are used as part of the documentation process allowing data to be extracted and analysed retrospectively. The data categories used for this study were hospital number, age, presenting complaint, department (minor vs major), and discharge diagnosis.

Data was extracted between the dates of March 13 to May 13, comparing attendances in both 2019 and 2020. Presenting complaint was used to compare all patients attending the emergency department (majors and minors). Diagnosis on discharge was used when comparing the MSK conditions presenting in the emergency department. The discharge data was used as it reflects a more accurate diagnosis of the condition. Data from the majors' area of the emergency department was excluded at this stage due to a large portion of missing data.

Initial analysis was performed comparing presenting complaints for the entire emergency department attendances. As patients are booked into the emergency department and categorised based on the presenting complaint. Number of attendances for each presenting complaint category was then compared between March 13 and May 13, 2019 to 2020. The data was then divided by the two areas where the patients were seen, data collected from patients placed in the majors' area of the emergency department was excluded at this stage due to a large proportion of missing data recorded at discharge. As the focus of the study was to assess the change in patterns of MSK injuries, presenting the data from limb problems placed under the minors' area was used to compare year groups.

As a secondary investigation, the age of patients presenting in the emergency department during a pandemic compared to the previous non-pandemic year was assessed to see if injury patterns changed within this demographic meaningfully.

\section{Results}

Overall attendances between the dates of March 13 and May 13 in the emergency department at Queens Hospital Burton reduced from 12,608 to 6,882, a reduction of 45.42\% when comparing 2019 to 2020 . Musculoskeletal presentations to the emergency department also declined. Back pain reduced by $58.88 \%$ from 321 in 2019 to 132 in 2020; neck pain reduced by $78.52 \%$ from 135 in 2019 to 29 in 2020, and limb problems reduced by 59.74\% from 2889 in 2019 to 1163 in 2020 (Table 1).

\begin{tabular}{|c|c|c|c|}
\hline Presenting Complaint & 2019 & 2020 & Change (\%) \\
\hline Abdominal pain & 889 & 489 & $-44.99 \%$ \\
\hline Abscess/infection & 154 & 122 & $-20.78 \%$ \\
\hline Alcohol related & 49 & 13 & $-73.47 \%$ \\
\hline Allergic reaction & 50 & 29 & $-42.00 \%$ \\
\hline Assault & 36 & 22 & $-38.89 \%$ \\
\hline Asthma & 48 & 21 & $-56.25 \%$ \\
\hline Back pain & 321 & 132 & $-58.88 \%$ \\
\hline Bite & 58 & 31 & $-46.55 \%$ \\
\hline Behaviour & 5 & 8 & $60.00 \%$ \\
\hline
\end{tabular}




\section{Cureus}

\begin{tabular}{|c|c|c|c|}
\hline Burn & 45 & 28 & $-37.78 \%$ \\
\hline Chemical exposure & 21 & 6 & $-71.43 \%$ \\
\hline Collapse & 195 & 122 & $-37.44 \%$ \\
\hline Crying baby & 7 & 2 & $-71.43 \%$ \\
\hline D\&V & 98 & 47 & $-52.04 \%$ \\
\hline Dental & 53 & 18 & $-66.04 \%$ \\
\hline Diabetic problem & 61 & 32 & $-47.54 \%$ \\
\hline Ear problem & 76 & 39 & $-48.68 \%$ \\
\hline Eye problem & 340 & 150 & $-55.88 \%$ \\
\hline Foreign body & 133 & 65 & $-51.13 \%$ \\
\hline Fits & 131 & 68 & $-48.09 \%$ \\
\hline Falls & 245 & 197 & $-19.59 \%$ \\
\hline Generally unwell & 2083 & 1386 & $-33.46 \%$ \\
\hline Gl bleed & 99 & 53 & $-46.46 \%$ \\
\hline Headache & 183 & 89 & $-51.37 \%$ \\
\hline Fascial injury & 254 & 87 & $-65.75 \%$ \\
\hline Head injury & 529 & 227 & $-57.09 \%$ \\
\hline Limping child & 29 & 4 & $-86.21 \%$ \\
\hline Limb problem & 2889 & 1163 & $-59.74 \%$ \\
\hline Major trauma & 16 & 13 & $-18.75 \%$ \\
\hline Mental health & 141 & 79 & $-43.97 \%$ \\
\hline Neck pain & 135 & 29 & $-78.52 \%$ \\
\hline Overdose & 169 & 103 & $-39.05 \%$ \\
\hline Palpitations & 128 & 83 & $-35.16 \%$ \\
\hline Pregnancy & 114 & 64 & $-43.86 \%$ \\
\hline PV bleed & 133 & 91 & $-31.58 \%$ \\
\hline Rash & 106 & 36 & $-66.04 \%$ \\
\hline Sexual acquired infection & 1 & 2 & $100.00 \%$ \\
\hline Social admission & 20 & 14 & $-30.00 \%$ \\
\hline Shortness of breath & 735 & 638 & $-13.20 \%$ \\
\hline Sorethroat & 98 & 44 & $-55.10 \%$ \\
\hline Testicle pain & 40 & 30 & $-25.00 \%$ \\
\hline Torso injury & 81 & 32 & $-60.49 \%$ \\
\hline Urinary problem & 307 & 189 & $-38.44 \%$ \\
\hline Worried parent & 81 & 21 & $-74.07 \%$ \\
\hline Wound & 216 & 246 & $-40.87 \%$ \\
\hline Total & 12608 & 6882 & $-45.42 \%$ \\
\hline
\end{tabular}

TABLE 1: Presenting complaints March 13 - May 13, 2019 vs 2020 
Although overall presentations of limb problems reduced by $59.74 \%$ when comparing the attendances for the entire emergency department. When comparing the attendances allocated to the minors' area, limb problems only decreased by $20.45 \%$, from 709 in 2019 to 564 in 2020 (Table 2). Soft tissue injuries decreased by $24.05 \%$ from 395 in 2019 to 300 in 2020 and fractures decreased by 7.96\% from 201 in 2019 to 185 in 2020 .

\begin{tabular}{|c|c|c|c|}
\hline Discharge Diagnosis & 2019 & 2020 & Change (\%) \\
\hline Abscess & 4 & 0 & $-100.00 \%$ \\
\hline Bursitis & 3 & 4 & $33.33 \%$ \\
\hline Cellulitis & 5 & 4 & $-20.00 \%$ \\
\hline CES & 2 & 0 & $-100.00 \%$ \\
\hline Chronic pain & 3 & 0 & $-100.00 \%$ \\
\hline DVT & 6 & 1 & $-83.33 \%$ \\
\hline Foreign Body & 2 & 0 & $-100.00 \%$ \\
\hline Fracture & 201 & 185 & $-7.96 \%$ \\
\hline Gout & 2 & 3 & $50.00 \%$ \\
\hline Haemarthrosis & 2 & 0 & $-100.00 \%$ \\
\hline Head injury & 8 & 0 & $-100.00 \%$ \\
\hline Infection & 1 & 3 & $200.00 \%$ \\
\hline Left before assessment & 2 & 0 & $-100.00 \%$ \\
\hline No Abnormality & 14 & 7 & $-50.00 \%$ \\
\hline Neurology & 1 & 0 & $-100.00 \%$ \\
\hline Osteoarthritis & 13 & 7 & $-46.15 \%$ \\
\hline Plaster Problem & 6 & 3 & $-50.00 \%$ \\
\hline Post-op Problem & 1 & 0 & $-100.00 \%$ \\
\hline Pulled Elbow & 2 & 2 & $0.00 \%$ \\
\hline Inflammatory Arthritis & 2 & 2 & $0.00 \%$ \\
\hline Sciatica & 8 & 9 & $12.50 \%$ \\
\hline Septic Arthritis & 2 & 2 & $0.00 \%$ \\
\hline Social Problem & 1 & 0 & $-100.00 \%$ \\
\hline Soft Tissue Injury & 395 & 300 & $-24.05 \%$ \\
\hline Tendinopathy & 9 & 12 & $33.33 \%$ \\
\hline Vascular & 2 & 0 & $-100.00 \%$ \\
\hline Wound & 12 & 20 & $66.67 \%$ \\
\hline Total & 709 & 564 & $-20.45 \%$ \\
\hline
\end{tabular}

\section{TABLE 2: Discharge diagnosis of patient presenting with "Limb problems" located in Minors}

CES: cauda equina syndrome, DVT: deep vein thrombosis

The percentage of the overall attendance which was classified as a limb problem decreased from $22.91 \%$ to $16.90 \%$, wounds and fractures discharged from the minors' area increased from $3.30 \%$ to $3.57 \%$ and $1.59 \%$ to $2.69 \%$ respectively (Table 3 ). 


\section{Cureus}

\begin{tabular}{|c|c|c|c|c|c|c|c|}
\hline Year & Total Attendances & Limb Problems & $\%$ & Wounds & $\%$ & Fractures located in Minors & $\%$ \\
\hline 2019 & 12,608 & 2,889 & $22.91 \%$ & 416 & $3.30 \%$ & 201 & $1.59 \%$ \\
\hline 2020 & 6,882 & 1,163 & $16.90 \%$ & 246 & $3.57 \%$ & 185 & $2.69 \%$ \\
\hline
\end{tabular}

TABLE 3: Percentage of the overall attendance made up of Limb problems, wounds and fractures in the emergency department and minors area.

The age range of patients presenting to the emergency department during a pandemic did not differ greatly when compared to non-pandemic times. The average age did increase by five years in 2020 (Table 4).

\begin{tabular}{|c|c|c|}
\hline Year & 2019 & 2020 \\
\hline Age range & 12days - 105years & 10days -101 years \\
\hline Average age & 45years & 50years \\
\hline
\end{tabular}

TABLE 4: Patient average and range of age presenting to the emergency department

Activity status of MSK injuries attending the minors' area of the emergency department differed significantly during times of a pandemic. Attendances relating to gardening increased from 13 to 28 , indoor recreation (such as hobbies) increased from 44 to 52, and Do It Yourself (DIY) from 37 to 52. In comparison attendances relating to road traffic collisions (RTC) reduced from 70 to eight, injuries at the gym reduced from 21 to eight, and football-related injuries reduced from 46 to 19 (Table 5).

\begin{tabular}{|c|c|c|c|}
\hline Activity & 2019 & 2020 & $\%$ change \\
\hline Gardening & 13 & 28 & $+115.4 \%$ \\
\hline Indoor recreation & 44 & 52 & $+40.9 \%$ \\
\hline DIY & 37 & 52 & $+40.5 \%$ \\
\hline Gym & 21 & 8 & $-61.9 \%$ \\
\hline Road Traffic Collision & 70 & 8 & $-88.6 \%$ \\
\hline Football & 46 & 19 & $-58.7 \%$ \\
\hline Walkıng & 336 & 184 & $-45.2 \%$ \\
\hline Social: Play/Recreation & 121 & 73 & $-39.7 \%$ \\
\hline Labour & 37 & 23 & $-37.8 \%$ \\
\hline
\end{tabular}

TABLE 5: Activity status during injury attending minor injury area of the emergency department DIY: Do It Yourself

The type of activities resulting in injuries and therefore attendance to the emergency department differed during the pandemic. Certain activities such as DIY housework, indoor recreations, and gardening increased during the pandemic whereas activities such as sports, driving, and work decreased, as shown in Figure 1. 


\section{Cureus}

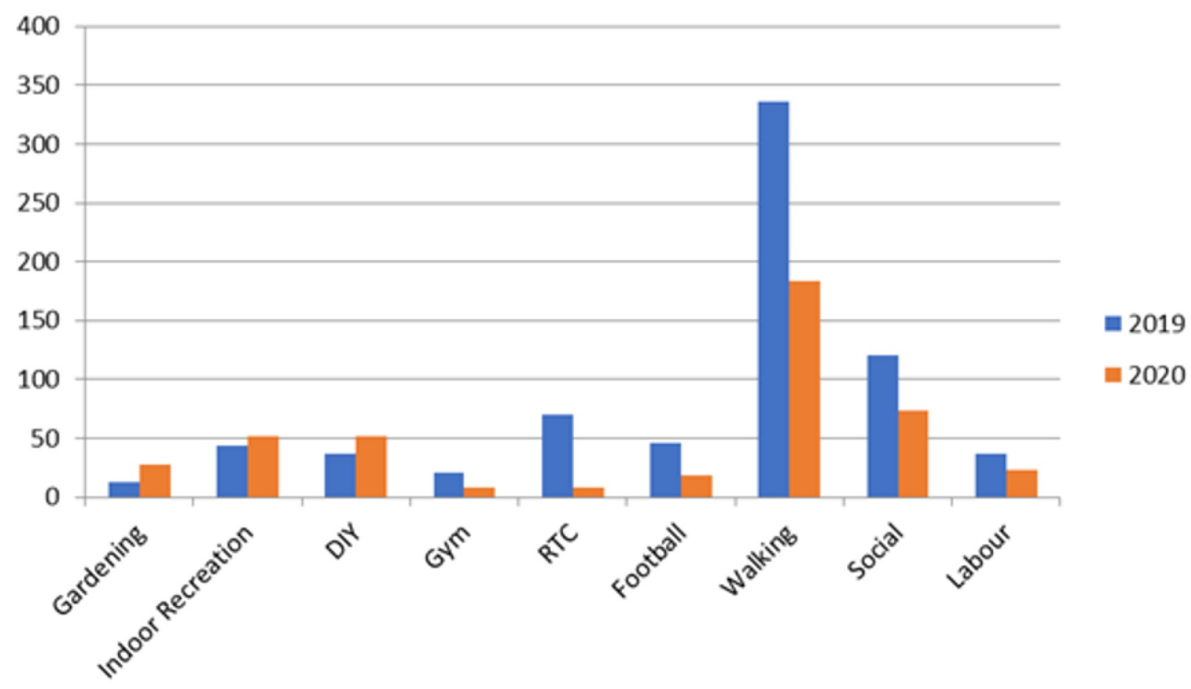

FIGURE 1: Activity status of musculoskeletal injuries presenting in minors area in the emergency department

DIY: Do It Yourself, RTC: road traffic collisions

Figure 2 shows the difference in activity status attending during times of a pandemic in comparison to nonpandemic times. Gardening-related injuries increased by $115.4 \%$, indoor recreation-related injuries increased by $40.9 \%$ and DIY increased by $40.5 \%$. In comparison, RTC reduced by $88.6 \%$, gym-related injuries reduced by $61.9 \%$, and football-related injuries reduced by $58.7 \%$.

\section{Difference from 2019 to 2020 (\%)}

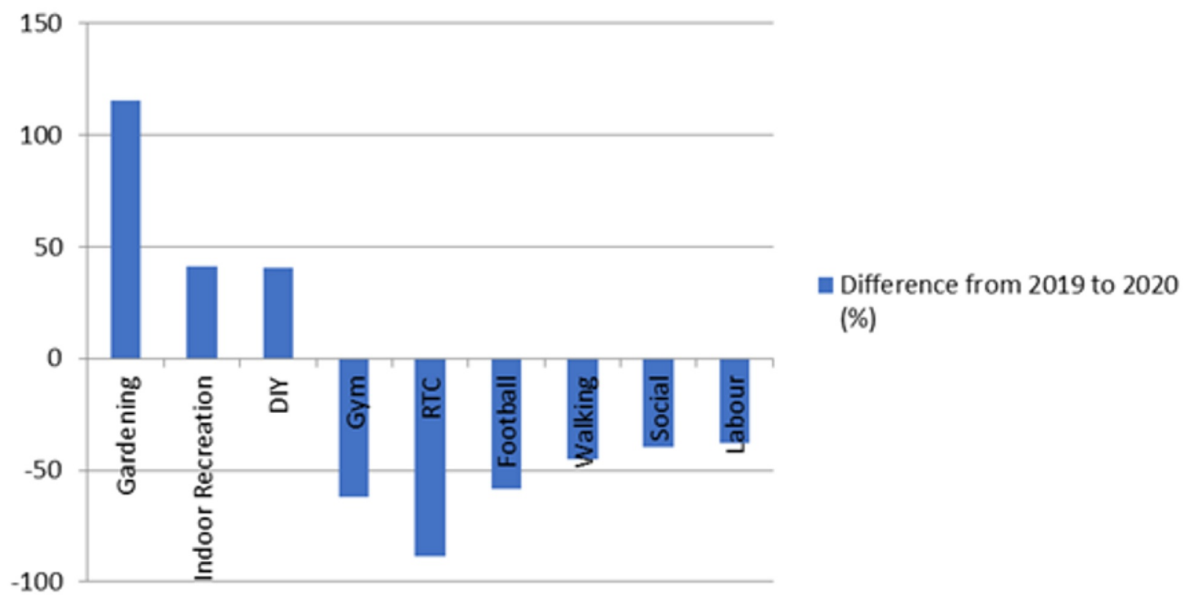

FIGURE 2: Activity status difference between 2019 and 2020.

DIY: Do It Yourself, RTC: road traffic collisions

\section{Discussion}

On March 232020 the United Kingdom government introduced six weeks of strict social distancing guidelines in response to the COVID-19 global epidemic. From March 1 to May 31, 2020, attendances in the emergency department decreased by $43.50 \%$ across England in comparison to the same months in 2019 . The greatest decline in attendances was seen during the month of April 2020, the middle of strict social distancing guidelines. Emergency department attendances at the Queens Hospitals in Burton on Trent decreased by $45.42 \%$, consistent with the average drop in attendances seen in emergency departments in England. The reduction in attendances is likely to be as a result of the strict social distancing guidelines. Consequently bars, restaurants and gyms were forced to close, contact sports stopped and many workers across the United Kingdom were either placed on a furlough scheme or encouraged to work from home. The 
reduced activity across the United Kingdom is likely to be a direct cause of the reduction in illness/injury and therefore reduction in attendees at the emergency department. Attendances may also be reduced due to much of the media coverage during this time stressing the importance of social distancing and the need to ease pressure on the National Health Service. This may have discouraged people from attending the emergency department partly due to fear of coming into contact with a contagious virus and partly due to the hope of easing pressures on the health services. Although overall emergency department attendances decreased by $45.42 \%$ at Queens Hospital Burton, the number of fractures seen in the minors' area of the department only decreased by 7.96\% from 201 (2019) to 185 (2020). Despite the large decline in patients coming to the emergency department and the strict social distancing guidelines there was still a significant number of fractures seen in the minors' area. Soft tissue injuries were also reduced from 395 (2019) to 300 (2020), a reduction of $24.05 \%$. There were still a large number of soft tissue injuries present in the emergency department during the period of reduced attendances, and like with the fracture this may in part be explained by an increase in DIY, gardening, and indoor recreation-related injuries. Although work and sport-related injuries decreased during the period of strict social distancing, DIY-related injuries increased. Labour related injuries fell by $37.8 \%$ during the period of social distancing when compared to 2019 , and gymrelated injuries (-61.9\%), driving-related injuries (-88.6\%), and football-related injuries (-58.7\%) also saw a significant decrease during the strict social distancing, as shown in Figure 1 and Figure 2 . The large decrease in these activities is explained by the population being encouraged to stay at home, this may also explain the increase in gardening (115.4\%), DIY (40.5\%) and indoor recreational activity (40.9\%)-related injuries. There was a large reduction in soft tissue injuries presenting during the strict social distancing guidance in comparison to fractures (-24.05\% for soft tissue injuries vs $-7.96 \%$ for fractures). This could indicate patients adopting a higher threshold to attending the emergency department with an injury and therefore more likely to try to self-manage at home. This could increase the rate of fractures or significant injuries seen within the emergency department but further research would be required to confirm this. The increased rate of fractures seen within the minors' area of the emergency department is reflected in the percentage of the overall attendance which increased from $1.59 \%$ in 2019 to $2.69 \%$ in 2020 .

There have been numerous articles analysing trauma patterns during the COVID-19 outbreak with the pattern of injury changing depending on the country, region and age of the patients [14-15]. During the COVID-19 pandemic emergency departments internationally saw a reported reduction in patients attending during relative periods of lockdown in each country [16-24]. Overall attendances to emergency departments were reported to have declined by as much as $68 \%$ in Italy [18-19] and 60\% in parts of the United States of America [20]. An article from Finland reported that although overall attendances reduced by 17\%, attendance related to MSK pain or injury reduced by 31\% [21]. In places such as Barcelona (Spain), trauma attendances reduced by as much as $86.1 \%$ [22]. Italy also reported a large reduction in the number of attendances related to trauma, reducing by $70 \%$. This fall in trauma attendances being partially explained by the low numbers of sport (-96.2\%) and road traffic collision (RTC) (-79.6\%) related injuries [19]. Reported data seen in this audit demonstrated similarities to the reduction in RTC-related injuries declining by $88.6 \%$ however injuries related to sports such as football only reduced by $58.7 \%$. A $52.1 \%$ decline in weekly trauma attendances were also reported in France during the period of lockdown [23]. This is consistent with the data seen in this audit with "Limb Problems" which declined by 59.74\% during the period of lockdown. One other explanation offered for the drop in trauma-related attendances is the significant decline in the number of patients under the age of 17 attending with injuries which decreased by $62 \%$ as reported in an article from Canada [24]. Environmental changes in temperature and season all impact on the trauma pattern with less patients presenting in the winter normally. Viral illnesses being worse at this time of year (winter) in intensity and number of cases then the impact may be less on musculoskeletal trauma services because patients behaviours are already different at this time of year [25]. There is a fear injuries may be missed as patients fear to attend but this does not seem to be born out locally and each region/hospital should monitor its patient flow closely to husband resources and deploy them to support the pandemic response [26].

\section{Limitations}

This study is a retrospective review of the audit data recorded during the completion of electronic documentation of patients attending the emergency department. Data from the majors' area of the emergency department is limited due to the accuracy in which the audit section of the electronic documentation is completed.

\section{Conclusions}

Attendances in the emergency department were greatly reduced during the COVID-19 pandemic, especially during the first lockdown. The rates of fractures and soft tissue injuries within the minors' area of the emergency department were also reduced but not at the same rate as the overall attendance. A large number of fractures and soft tissue injuries still presented to the emergency department despite reduced national activity. These attendances may be as a result of the increased rate of DIY-related injuries and altered patient/social behaviour due to lockdown, social distancing, and seasons/weather. Further research would be required to investigate the changing patterns of behaviour especially as we enter a second wave of cases. 


\section{Additional Information \\ Disclosures}

Human subjects: Consent was obtained or waived by all participants in this study. Animal subjects: All authors have confirmed that this study did not involve animal subjects or tissue. Conflicts of interest: In compliance with the ICMJE uniform disclosure form, all authors declare the following: Payment/services info: All authors have declared that no financial support was received from any organization for the submitted work. Financial relationships: All authors have declared that they have no financial relationships at present or within the previous three years with any organizations that might have an interest in the submitted work. Other relationships: All authors have declared that there are no other relationships or activities that could appear to have influenced the submitted work.

\section{References}

1. Du Toit A: Outbreak of a novel coronavirus. Nat Rev Microbiol. 2020, 18:123-123. 10.1038/s41579-0200332-0

2. He F, Deng Y, Li W: Coronavirus disease 2019: what we know? . J Med Virol. 2020, 92:719-725. 10.1002/jmv.25766

3. Sohrabi C, Alsafi Z, O'Neill N, et al.: World Health Organization declares global emergency: a review of the 2019 novel coronavirus (COVID-19). Int J Surg. 2020, 76:71-76. 10.1016/j.ijsu.2020.02.034

4. Moss P, Barlow G, Easom N, Lillie P, Samson A: Lessons for managing high-consequence infections from first COVID-19 cases in the UK. Lancet. 2020, 395:46. 10.1016/S0140-6736(20)30463-3

5. Rothan HA, Byrareddy SN: The epidemiology and pathogenesis of coronavirus disease (COVID-19) outbreak . J Autoimmun. 2020, 109:102433. 10.1016/j.jaut.2020.102433

6. Li Q, Guan X, Wu P, et al.: Early transmission dynamics in Wuhan, China, of novel coronavirus-infected pneumonia. N Engl J Med. 2020, 382:1199-1207. 10.1056/NEJMoa2001316

7. Chan JF, Yuan S, Kok K-H, et al.: A familial cluster of pneumonia associated with the 2019 novel coronavirus indicating person-to-person transmission: a study of a family cluster. Lancet. 2020, 395:514-23. 10.1016/S0140-6736(20)30154-9

8. Cucinotta D, Vanelli M: WHO declares COVID-19 a pandemic . Acta Bio-Medica Atenei Parm. 2020, 91:15760. 10.23750/abm.v91i1.9397

9. COVID-19: Government Announces Moving Out of Contain Phase and Into Delay . (2020). Accessed: October 2020: https://www.gov.uk/government/news/covid-19-government-announces-moving-out-of-containphase-and-into-delay.

10. Iacobucci G: Covid-19: UK lockdown is "crucial” to saving lives, say doctors and scientists . BMJ. 2020, 268:1204. 10.1136/bmj.m1204

11. Mayhew K, Anand P: COVID-19 and the UK labour market. Oxford Rev Econ Policy. 2020, 36:215-224. 10.1093/oxrep/graa017

12. Mahase E: Covid- 19: schools set to close across UK except for children of health and social care workers . BMJ. 2020, 368:m1140. 10.1136/bmj.m1140

13. Statistics » A\&E Attendances and Emergency Admissions 2020-21 . (2020). Accessed: October 2020: https://www.england.nhs.uk/statistics/statistical-work-areas/ae-waiting-times-and-activity/aeattendances-and-emergen....

14. Nabian MH, Vosoughi F, Najafi F, et al.: Epidemiological pattern of pediatric trauma in COVID-19 outbreak: data from a tertiary trauma center in Iran. Injury. 2020, 51:2811-2815. 10.1016/j.injury.2020.09.015

15. Staunton P, Gibbons JP, Keogh P, Curtin P, Cashman JP, O'Byrne JM: Regional trauma patterns during the COVID-19 pandemic. Surgeon. 2020, 13:10.1016/j.surge.2020.08.003

16. Wongtanasarasin W, Srisawang T, Yothiya W, Phinyo P: Impact of national lockdown towards emergency department visits and admission rates during the COVID-19 pandemic in Thailand: a hospital-based study. Emerg Med Australas. 2020, 18:10.1111/1742-6723.13666

17. Mahmassani D, Tamim H, Makki M, Hitti E: The impact of COVID-19 lockdown measures on ED visits in Lebanon. Am J Emerg Med. 2020, 2:0735-6757. 10.1016/j.ajem.2020.11.067

18. Giamello JD, Abram S, Bernardi S, Lauria G: The emergency department in the COVID-19 era. Who are we missing?. Eur J Emerg Med. 2020, 27:305-306. 10.1097/MEJ.0000000000000718

19. Dolci A, Marongiu G, Leinardi L, Lombardo M, Dessì G, Capone A: The epidemiology of fractures and muskulo-skeletal traumas during COVID-19 lockdown: a detailed survey of 17.591 patients in a wide Italian metropolitan area. Geriatr Orthop Surg Rehabil. 2020, 10.1177/2151459320972673

20. Giannouchos TV, Biskupiak J, Moss MJ, Brixner D, Andreyeva E, Ukert B: Trends in outpatient emergency department visits during the COVID-19 pandemic at a large, urban, academic hospital system. Am J Emerg Med. 2020, 9:20-26. 10.1016/j.ajem.2020.12.009

21. Kuitunen I, Ponkilainen VT, Launonen AP, Reito A, Hevonkorpi TP, Paloneva J, Mattila VM: The effect of national lockdown due to COVID-19 on emergency department visits. Scand J Trauma Resusc Emerg Med. 2020, 4:114-10.

22. Esteban PL, Querolt Coll J, Xicola Martínez M, Camí Biayna J, Delgado-Flores L: Has COVID-19 affected the number and severity of visits to a traumatology emergency department?. Bone Jt Open. 2020, 1:617-620. 10.1302/2633-1462.110.BJO-2020-0120.R1

23. Crenn V, El Kinani M, Pietu G, et al.: Impact of the COVID-19 lockdown period on adult musculoskeletal injuries and surgical management: a retrospective monocentric study. Sci Rep. 2020, 10:22442. 10.1038/s41598-020-80309-x

24. Keays G, Friedman D, Gagnon I: Injuries in the time of COVID-19. Health Promot Chronic Dis Prev Can. 2020, 40:336-341. 10.24095/hpcdp.40.11/12.02

25. Hind J, Lahart IM, Jayakumar N, Athar S, Fazal MA, Ashwood N: Seasonal variation in trauma admissions to a level III trauma unit over 10 years. Injury. 2020, 51:2209-2218. 10.1016/j.injury.2020.07.014 


\section{Cureus}

26. Baugh JJ, White BA, McEvoy D, Yun BJ, Brown DF, Raja AS, Dutta S: The cases not seen: patterns of emergency department visits and procedures in the era of COVID-19. Am J Emerg Med. 2020, 5:10.1016/i.ajem.2020.10.081 